\title{
Case Report: Myocardial Bypass in Left Descending Artery — A Rare Congenital Anomaly
}

Vergílio Pereira Carvalho, ${ }^{1 \oplus}$ Eraldo Ribeiro Ferreira Leão de Moraes, ${ }^{1}$ João Emílio Hanum Paes, ${ }^{2}$ Daniela Textor, ${ }^{1}$ Hugo Leonardo Shigenaga Ribeiro, ${ }^{3 \oplus}$ Amara Chebli Baptista, ${ }^{1 \oplus}$ Stephanie Borges Vilela, ${ }^{1 \oplus}$ Ana Paula Fontana, ${ }^{1}$ Isabella Beatriz Silva Rocha, ${ }^{\circledR}$ Jair Pereira Melo Junior ${ }^{\circledR}$

Universidade de Rio Verde, ${ }^{\prime}$ Rio Verde, GO-Brazil

Centro Universitário de Atenas, ${ }^{2}$ Paracatu, MG - Brazil

Irmandade da Santa Casa de Misericórdia de São Paulo, ${ }^{3}$ São Paulo, SP - Brazil

\begin{abstract}
Myocardial bypass (MB) is known to have scientific relevance and is present in several studies with great statistical significance regarding its clinical manifestations and complications. There are still questions about MB in its relationship with heart disease and repercussion in life-threatening conditions. We present a case report of a $\mathrm{MB}$ in the left anterior descending coronary artery, whose objective is to identify this rare congenital anomaly and to highlight the patient's clinical outcome in order to elicit greater contributions about the presence of this variant in the emergency room, its diagnosis by angiography and therapeutic management.
\end{abstract}

\section{Introduction}

Myocardial bypass is defined as a portion of the myocardial tissue that bypasses a segment of the coronary artery, with a greater number of cases in the left anterior descending coronary artery. ${ }^{1}$ The true prevalence of the myocardial bypass is not fully recognized. What is known is that myocardial bypasses are usually found over the left anterior descending coronary artery and are rarely found over the right coronary artery or the left circumflex coronary artery. ${ }^{2}$

\section{Keywords}

Myocardial Bridging; Heart Defects, Congenital; Myocardial Ischemia; Cardiac Electrophysiology; Angiography/methods.
Although myocardial bypass is generally considered a benign condition, several studies have shown an association between the myocardial bypass and acute coronary syndromes, chest pain, arrhythmia, left ventricular dysfunction, Takotsubo cardiomyopathy and sudden death., 3 Shwarz et al., ${ }^{5}$ proposed the following classification of myocardial bypass in the absence of coronary artery disease: type $\mathrm{A}$, clinical symptoms and no objective signs of ischemia; type B, clinical symptoms and objective signs of ischemia by noninvasive stress testing; and type $\mathrm{C}$, clinical symptoms and objective abnormal intracoronary hemodynamics (by quantitative coronary assessment/coronary flow reserve/intracoronary Doppler).

In addition, it is understood that beta-blockers or calcium channel antagonists are generally the first line of treatment in type A and B patients, whereas patients with refractory type $C$ myocardial bypass are treated with surgical interventions such as myotomy (unroofing) or coronary artery bypass surgery or coronary stenting as a second-line option. ${ }^{5,6}$

We present a rare case of myocardial bypass in the left anterior descending coronary artery in a 55-year-old female patient, where we will discuss drug treatment and coronary intervention therapy in association with clinical outcomes.

\section{Case report}

Previously healthy 55-year-old female patient was initially admitted to another hospital. She reported three days of constant severe oppressive chest pain radiating to the left upper limb, associated with cold, intermittent

Mailing Address: Vergílio Carvalho

Rua 08, n. 04. Postal Code: 75906-060. Vila Renovação, Rio Verde, GO - Brazil.

E-mail: vergilio_carvalho@hotmail.com 
sweating, presyncope and dyspnea on moderate exertion. The patient denies fever, nausea, vomiting, genitourinary disorders, history of systemic arterial hypertension, diabetes mellitus and allergies. She reported that, for most of the day, she presented normal levels of vigilance, concentration, and was very anxious, distressed and worried. Subsequently, myocardial necrosis markers were serialized, showing creatine kinase (CK) -MB of $48 \mathrm{U} / \mathrm{I}$ (reference value $25 \mathrm{U} / \mathrm{I}$ ) and negative troponin. Admission electrocardiogram showed slightly abnormal ventricular repolarization in the inferior and septal walls.

The patient was transferred to our Interventional Cardiology service. Physical examination revealed poor general condition, no pain improvement, nasal catheter 2 $\mathrm{L} / \mathrm{min}$ of $\mathrm{O}_{2}$, the patient was agitated, lucid and oriented in time and space, pale $(++/ 4+)$, acyanotic, anicteric, afebrile and hydrated. Blood pressure 154 x $98 \mathrm{mmHg}$, regular strong pulses with 76 beats per minute, heart rate 76 beats per minute, respiratory rate of 21 breaths per minute, $93 \%$ oxygen saturation in ambient air. Inspection of non-visible and non-palpable ictus cordis cardiovascular system in two digital pulps, cardiac auscultation with regular twostroke heart rhythm and normophonetic heart sounds without murmurs. Examination of the respiratory tract without further abnormalities. A new electrocardiogram revealed (Figure 1) anterior ischemia and positive serialized troponin. Anti-ischemic therapeutic measures (acetylsalicylic acid $100 \mathrm{mg}$, clopidogrel $75 \mathrm{mg}$, sodium enoxaparin $40 \mathrm{mg}$ every 12 hours, metoprolol succinate $50 \mathrm{mg}$, atorvastatin $40 \mathrm{mg}$ ) were then initiated.

Coronary angiography was chosen (Figure 2) and $30 \%$ lesion was found in the proximal third of the left anterior descending artery and myocardial bridge in the middle third. Absence of atherosclerotic disease implied stress echocardiography to assess previous ischemia possibly caused by the myocardial bypass. Stress echocardiography (Figure 3) was performed under physical stress demonstrating grade I diastolic dysfunction, diffuse hypokinesia with mild systolic dysfunction, more pronounced hypokinesia in the apical region and thickened mitral valve with mild regurgitation, thus contributing to the correlation of this patient's existing myocardial bypass with the ischemia findings.

Bisoprolol (beta-blocker) $2.5 \mathrm{mg}$ in the morning and citalopram (selective serotonin receptor inhibitor) $5 \mathrm{mg}$ daily were prescribed, with discontinuation of platelet antiaggregant and anticoagulant, with no recurrence of in-hospital chest pain. The patient was discharged in good clinical condition.

\section{Discussion}

It is understood that the clinical and pathophysiological factors that may unmask or exacerbate myocardial

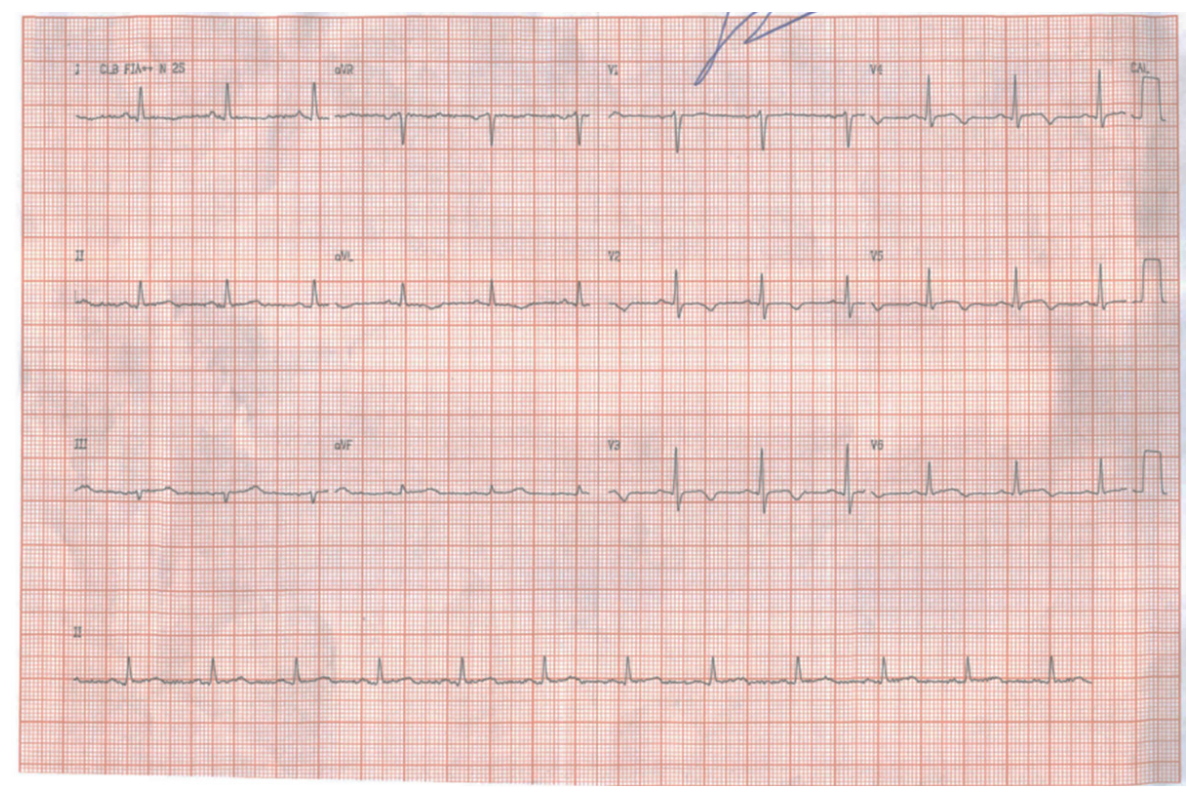

Figure 1 - Admission electrocardiogram at the Interventional Cardiology service, showing previous ischemia. 


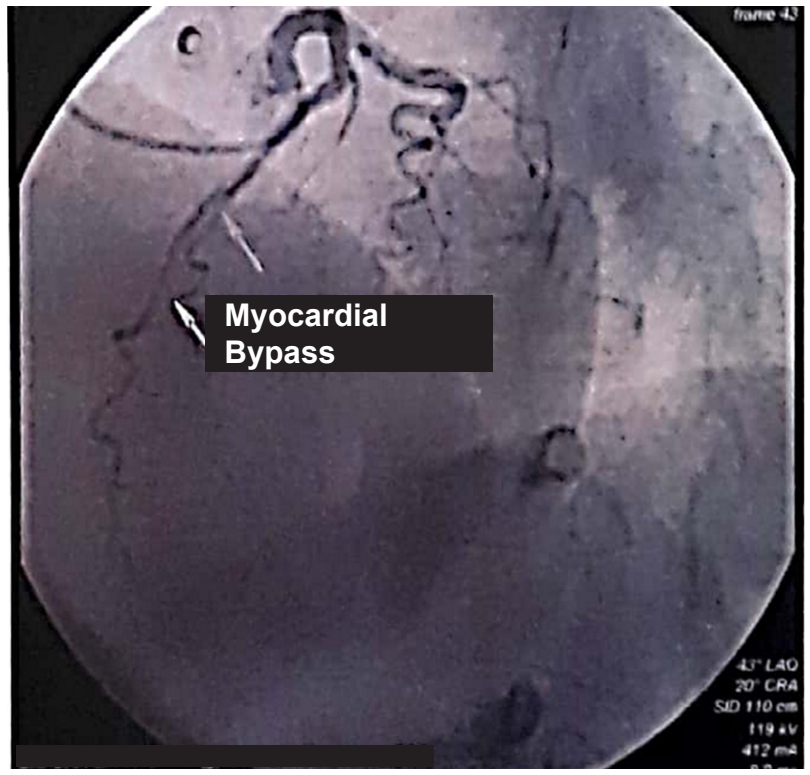

Figure 2 - Coronary angiography revealing myocardial bypass in the middle third in left axial anterior descending coronary artery projection during systole.

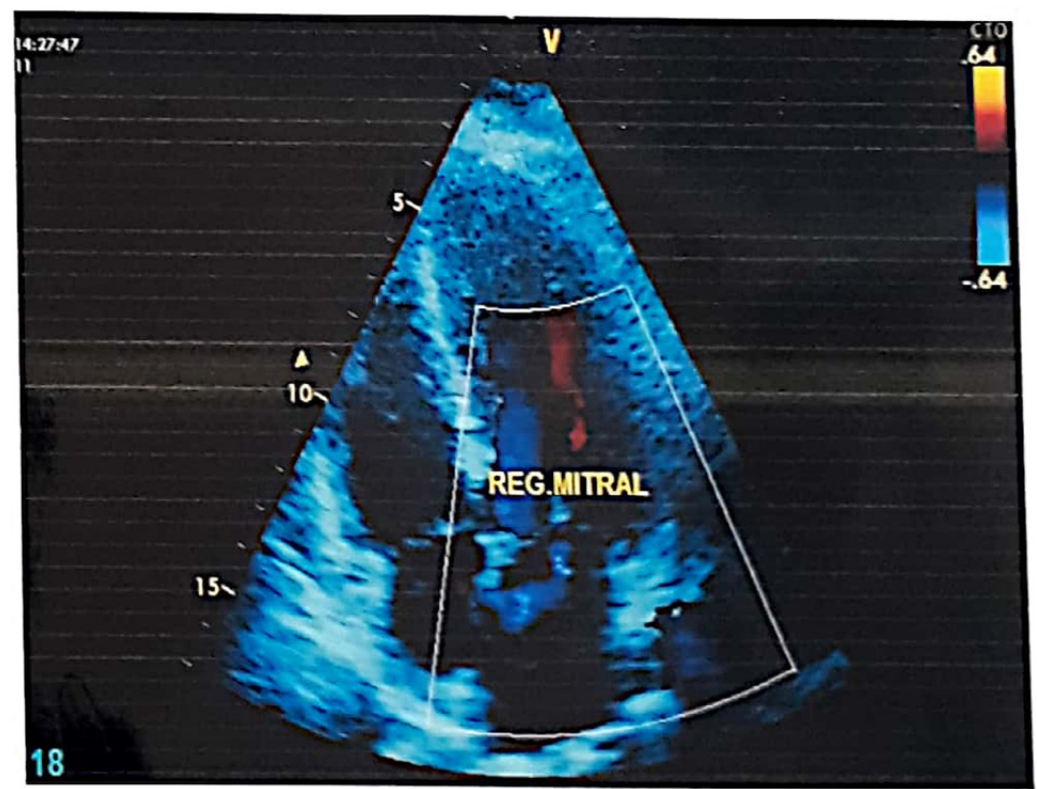

Figure 3 - Stress echocardiography showing thickened mitral valve with mild regurgitation and diffuse hypokinesia with mild systolic dysfunction.

bypass are the patient's age, heart rate, left ventricular hypertrophy and the presence of coronary atherosclerosis. ${ }^{6}$ In this regard, the patient in this report has thickened mitral valve corroborating studies that favor the onset of symptoms of chest pain, similar to those of acute coronary syndrome. Increased left ventricular diastolic 
dysfunction associated with aging, left ventricular hypertrophy and coronary atherosclerosis may worsen not only the mismatch of oxygen supply imposed by the myocardial bypass but also reduce microvascular reserve by microvasculature compression. ${ }^{6,7}$

In addition, the patient had generalized anxiety and diastolic dysfunction and stress echocardiography revealed that. Similarly, studies clarify that increased sympathetic activity due to vigorous physical exercise or situations of emotional stress and anxiety reduce myocardial flow and perfusion by decreasing diastolic perfusion time in line with increased epicardial coronary vasoconstriction and myocardial bypass contraction over the left anterior descending coronary artery. ${ }^{8}$ Another factor is the coronary spasm that persists during diastole because the arterial vascular smooth muscle relaxation time is delayed compared to the diastole duration, especially associated with the aforementioned circumstances, which contributes to worsening of coronary perfusion. ${ }^{8}$

The impairment resulting from diastolic flow has two secondary pathophysiological consequences related to heart rate and severity and duration of epicardial arterial compression. These consequences are subendocardial/transmural ischemia and septal ischemia. ${ }^{6-9}$ The latter is caused by depressurization of septal branches within the myocardial bypass, resulting in decreased intravenous perfusion pressure due to a Venturi effect. This is elucidated because the pressure difference starts with the Bernoulli equation, which can be written as follows: p1 $+1 / 2$ p.v12 = constant. ${ }^{9}$

The terms of this equation are

$\mathrm{p}=$ Pressure exerted by the fluid $(\mathrm{pa})$;

$\rho=$ fluid density $\left(\mathrm{kg} / \mathrm{m}^{3}\right)$;

$\mathrm{v}=$ Flow rate $(\mathrm{m} / \mathrm{s})$

As the myocardial bypass creates an environment with two distinct regions in the left anterior descending coronary artery, applying this equation gives us: $\mathrm{p} 1+$ $1 / 2 \rho . v 12=p 2+1 / 2 \rho \cdot v 22$. Because the myocardial bypass area is thinner, it will have a higher flow velocity, so equality in the Bernoulli equation will only be maintained if the pressure in this area is lower, which actually occurs in the septal branches within the myocardial bypass. ${ }^{9}$

Several factors have been postulated to explain the differences between the rates of myocardial bypass observed at necropsy compared with angiographic observations. Reasons include: myocardial bypass thickness and length, reciprocal orientation of the coronary artery and myocardial fibers, presence of atheromatous plaques, presence of aortic tract obstruction (in which the systolic tension that develops in the myocardial bypass exceeds intracoronary artery pressure), presence of a proximal coronary obstruction (which decreases the distal intracoronary pressure), myocardial contractility status, heart rate at the time of angiography, and examiner experience. ${ }^{10}$

The original definition and classification of myocardial bypass was developed with invasive coronary angiography. On the other hand, due to the lack of a real gold standard for the diagnosis of myocardial bypass, several forms of diagnosis were used to assess its anatomical, morphological and functional significance. Besides, myocardial bypass may cause significant diastolic pressure gradients and artificially normal or negative systolic pressure gradients. This phenomenon can produce an artificial increase in the mean pressure used to determine cardiac injury by using fractional reverse flow (FRR), which is the measurement of coronary artery blood flow in the event of some type of obstruction, resulting in underestimation of the myocardial bypass hemodynamic significance. ${ }^{11}$ What is observed with stress echocardiography is that as the myocardial bypass generates dynamic stenosis caused by chronotropic and inotropic stimulation, the simple dilation of the artery with adenosine underestimates the hemodynamic significance of most bypasses. ${ }^{11}$ Therefore, this suggests an element of coronary spasm or fixed stenosis rather than identifying significant myocardial bypass activity. ${ }^{11}$

When invasive tools to assess the ischemic potential of myocardial bypass are not available, functional noninvasive imaging tests may be helpful. Stress echocardiography, stress magnetic resonance imaging, single-photon emission computed tomography, and positron emission tomography can detect myocardial bypass in the left anterior descending coronary artery. Compared to others, cardiac magnetic resonance imaging has a better spatial resolution to detect segmental and subendocardial perfusion defects. ${ }^{12}$

Regarding drug treatment, considering the classification proposed by Schwarz et al., ${ }^{5}$ described above, data from a 5-year follow-up based on this classification showed that types $B$ and $C$ responded well to beta-blockers or calcium channels antagonists, 
while patients with refractory type C myocardial bypasses were better treated with stent placement. ${ }^{6}$ Beta-blockers are considered first-line therapy because of their negative chronotropic and inotropic effects and because of decreased sympathetic nervous system activation by exertion or induction of physical and emotional stress. ${ }^{13}$

Vasodilators such as nitroglycerin or sodium nitroprusside are not recommended because they may worsen symptoms due to increased systolic compression of the tunneled artery, induce tachycardia and proximal vessel dilation, which may worsen flow reversal in the proximal coronary segment. ${ }^{14}$ On the other hand, ivabradine reduces heart rate by specifically inhibiting If-ion channels (activated during action potential repolarization) and can be considered as therapy alone or associated with a lower dose of beta-blockers and calcium channel antagonists. ${ }^{14}$

A lifestyle change is recommended because of the risk of developing myocardial bypass-induced atherosclerosis. Antiplatelet therapy should be considered when subclinical atherosclerosis is detected.

\section{Conclusion}

Based on previous pathophysiological concerns and the case report of a rare congenital anomaly, healthcare and treatment should focus on relieving potential triggers and hemodynamic disorders that worsen myocardial bypass, such as hypertension, ventricular hypertrophy, increased heart rate, reduced diastolic coronary filling duration, inadequate coronary artery contractility and compression. ${ }^{7-8}$ Consequently, betablockers are considered the first-line therapy because of their negative chronotropic and inotropic effects, and because of decreased sympathetic nervous system activation, either by exertion or induction of physical and emotional stress. ${ }^{6}$ Thus, it was chosen to use this class of drugs associated with a selective serotonin reuptake inhibitor due to the generalized anxiety disorder that may cause neurovegetative symptoms and increased heart rate. ${ }^{7}$

\section{Author contributions}

Conception and design of the research: Carvalho VP, Rocha IBS. Acquisition of data: Baptista AC, Vilela SB. Analysis and interpretation of the data: Paes JEH, Textor D. Writing of the manuscript: Carvalho VP, Júnior JPM. Critical revision of the manuscript for intellectual content: Carvalho VP, Moraes ERFL, Ribeiro HS, Fontana AP, Júnior JPM.

\section{Potential Conflict of Interest}

No potential conflict of interest relevant to this article was reported.

\section{Sources of Funding}

There were no external funding sources for this study.

\section{Study Association}

This article is part of the thesis of free teaching submitted by Vergílio Carvalho, from Universidade de Rio Verde.

\section{Ethics approval and consent to participate}

This study was approved by the Ethics Committee of the CEP - UNIVR under the protocol number 2.557.630. All the procedures in this study were in accordance with the 1975 Helsinki Declaration, updated in 2013. Informed consent was obtained from all participants included in the study.

\section{References}

1. Paraskevas G, Koutsouflianiotis K, Iliou K. Myocardial bridge over the left anterior descending coronary artery: a case report and review of the literature. J Res Med Sci. 2017 Oct 31;22:113.

2. Kiris T, Koprulu D, Elmali M, Zeren G, Erdogan G. A rare case of myocardial bridge involving left anterior descending, obtuse marginal and ramus intermediate coronary arteries. Kardiochir Torakochirurgia Pol. 2016;13(4):368-9.

3. Cerrato E, Barbero U, D'Ascenzo F, Taha S, Biondi-Zoccai G, Omede P, et al. What is the optimal treatment for symptomatic patients with isolated coronary myocardial bridge? a systematic review and pooled analysis. J Cardiovasc Med. 2017;18(10):758-70.

4. Fallavollita L, Halasz G, Piseri M, Biasini V. Anomalous origin of left circumflex artery from aorta and left anterior descending coronary artery myocardial bridge: an unusual association between two coronary artery anomalies. Indian Heart J. 2017;69(3):415-6.

5. Schwarz ER, Gupta R, Haager PK, Vom Dah J, Klues HG, Minartz J, et al. Myocardial bridging in absence of coronary artery disease: proposal of a new classification based on clinical-angiographic data and long-term follow-up. Cardiology. 2009;112(1):13-21.

6. Tarantini G, Migliore F, Cademartiri F, Fraccaro C, Iliceto S. Left anterior descending artery myocardial bridging. J Am Coll Cardiol. 2016;68(25):2887-99. 
7. Corban MT, Hung OY, Eshtehardi P, Rasoul-Arzrumly E, McDaniel M, Mekonnen G, et al. Myocardial bridging: contemporary understanding of pathophysiology with implications for diagnostic and therapeutic strategies. J Am Coll Cardiol. 2014;63(22):2346-55.

8. Gould KL, Johnson NP. Imaging coronary blood flow in AS: let the data talk, again. J Am Coll Cardiol. 2016;67(12):1423-26.

9. Gould KL, Kirkeeide R, Johnson NP. Coronary branch steal: experimental validation and clinical implications of interacting stenosis in branching coronary arteries. Circ Cardiovasc Imaging. 2010;3(6):701-9.

10. Alegria JR, Herrmann J, Holmes DR Jr, Lerman A, Rihal CS. Myocardial bridging. Eur Heart J. 2005;26(12):1159-68.
11. Tremmel JA, Schnittger I. Myocardial bridging. J Am Coll Cardiol. 2014;64(20):2178-9.

12. Koo HJ, Yang DH, Kim YH, Kang JW, Kang SJ, Kweon J, et al. CTbased myocardial ischemia evaluation: quantitative angiography, transluminal attenuation gradient, myocardial perfusion, and CT-derived fractional flow reserve. Int J Cardiovasc Imaging. 2016;32(Suppl 1):1-19.

13. Angelini P, Trivellato M, Donis J, Leachman RD. Myocardial bridges: a review. Prog Cardiovasc Dis. 1983;26(1):75-88.

14. Hongo $\mathrm{Y}$, Tada H, Ito K, Yasumura Y, Miyatake K, Yamagishi M. Augmentation of vessel squeezing at coronary-myocardial bridge by nitroglycerin: study by quantitative coronary angiography and intravascular ultrasound. Am Heart J. 1999;138(2 Pt 1):345-50. 